\title{
Morpho-Anatomical Changes in Roots of Chickpea (Cicer arietinum L.) under Drought Stress Condition
}

\author{
Nayab Saeed ${ }^{1}$, Nazimah Maqbool ${ }^{1}$, Muhammad Haseeb $^{2}$ and Rumana Sadiq ${ }^{3}$ \\ 1. Department of Botany, University of Agriculture, Faisalabad 38040, Pakistan \\ 2. Department of Agronomy, University of Agriculture, Faisalabad 38040, Pakistan \\ 3. Department of Botany, Government College Women University, Faisalabad 38040, Pakistan
}

\begin{abstract}
Chickpea (Cicer arietinum L.) is a crop cultivated in semi-arid and rainfed areas of Pakistan and it experiences terminal drought stress. In this paper, the morpho-anatomical study regarding roots of chickpea was carried out to investigate the drought adaptation strategies. Twelve cultivars of chickpea were grown in pots under drought stress of $70 \%$ and $35 \%$ field capacity in addition to control (100\%). Root segments of mature chickpea plants were sectioned in $2 \mathrm{~cm}$ from root-shoot junction and used for making transverse sections. The development of sleeve and stele tissues and their proportion were markedly influenced by moisture availability to the root system. Roots length, fresh and dry weight, and number of secondary roots were decreased under field capacity of 70\% and 35\% as compared to control in 12 cultivars of chickpea. Root epidermis and cortex of CH47/04 consisted of cells with thickened walls and with 2-3 cell layers of sclerenchymatous cells below the epidermis. Increased number of medullary rays and high vascular region was observed in cultivars CH120/04, CH47/04, CH587/05 and CH87/02. Anatomical studies showed that CH47/04 was highly tolerant among 12 cultivars of chickpea, while CH587/05 and CH87/02 behaved moderately under both levels of drought stress (70\% and 35\% field capacity).
\end{abstract}

Key words: Chickpea, field capacity, sleeve, vascular region, cultivars.

\section{Introduction}

Chickpea is one of the oldest legumes known for its rich protein contents that make it important component of human diet [1]. It is a crop of rainfed areas, cultivated mainly in Thal and Khaber Pakhtunkhawa areas of Pakistan [2]. As it is grown in limited water conditions, so chickpea often experiences terminal drought stress [3]. Adaptation strategy opted by plants makes their survival possible under drought stress conditions [4].

Plants experience drought either when the water supplied to the roots becomes limited or when the transpiration rate increases [5]. These two conditions often coincide under arid and semi-arid climates. The responses of plants to drought stress are highly complex, involving deleterious and adaptive changes. Drought stress affects water status in plants. Leaf

Corresponding author: Nazimah Maqbool, Ph.D., research fields: stress physiology and histology. water potential and relative water content are useful means for determining the physiological water status of plants [6].

According to statistics, the percentage of drought affected land areas has been doubled since the 1970s to the early 2000s in the world [7]. Drought is a world-spread problem seriously influencing grain production and quality of crops, and with increasing population and global climate change, the situation is more serious [8]. The problem of drought will be greater in future due to global climate change [9].

Drought stress is considered to be a moderate loss of water, which leads to stomatal closure and limitation of gas exchange. Desiccation is much more extensive loss of water, which can potentially lead to gross disruption of metabolism and cell structure, and eventually to the cessation of enzyme catalyzed reactions [10].

Plant responses to drought depend on the 
physiological and anatomical properties of tissue components that regulate the transmission of stress effects to the tissues [11]. Roots are the primary organ for the absorption of water and minerals, and drought greatly affects the number and size of water conducting elements, a functional aspect related to root anatomy [12]. Reduction in cortical cell size and number, lignification of epidermal and exodermal cells and layering of sclerenchymatous cells in neighbour of cortical cells are due to the deposition of lignin, and suberins is one of another modifications under water deficit condition [13].

Drought tolerant cultivars tend to have a greater root biomass, i.e., a greater root-to-shoot ratio and deeper root profiles in common beans and pea [14], cowpea [15], soy bean, pea and chickpea [16]. A high ratio of deep root weight to shoot weight was also found to maintain high plant water potentials and had a positive effect on yield under stress [17]. The study of drought related root avoidance and modification attributes will be beneficial in engineering genetically modified chickpea.

The objective of the present study was to quantify differences in morpho-anatomy of root among 12 chickpea cultivars under different levels of drought stress to evaluate the effect of water deficiency on chickpea root anatomical structure and component.

\section{Materials and Methods}

\subsection{Plant Materials and Experimental Details}

Twelve chickpea (Cicer arietinum L.) cultivars were tested for variation of their root anatomy in relation to their drought tolerance level. Seeds of twelve chickpea cultivars (CH120/04, CH119/04, CM45/04, CH23/00, CH4/02, CH38/00, CH87/02, CH42/03, CH34/03, CM613/05, CH587/05 and CH47/04) were obtained from Nuclear Institute for Agriculture and Biotechnology (NIAB), Faisalabad, Pakistan. Plastic pots (28 cm length $\times 25 \mathrm{~cm}$ diameter) experiment was conducted in Old Botanical Garden, University of Agriculture, Faisalabad, Pakistan in 2015. Three levels of drought treatments were maintained at a filed capacity of $100 \%, 70 \%$ and $35 \%$, respectively. The experiment was laid out in a completely randomized design with two factors and three replications of each experimental unit. Pots were filled with loamy soil (10 $\mathrm{kg}$ ) and irrigated with normal water. When the moisture contents were at field capacity, seeds of different cultivars were hand sown. Thinning of plants was done $15 \mathrm{~d}$ after complete germination to maintain five plants per pot.

Soil samples of $200 \mathrm{~g}$ each of the soil used in the experiment were taken at the time of filling of plastic pots, sealed in plastic bags, labelled and brought in laboratory for determination of field capacity. These soil samples were then incubated at $105^{\circ} \mathrm{C}$ for $24 \mathrm{~h}$. These oven dried samples were weighed and averaged for the determination of the total moisture contents of the soil at the time of sowing the seeds of chickpea cultivars. Then, the saturation percentage of the samples of $100 \mathrm{~g}$ each of this oven dried soil was approximated by measuring and then averaging the distilled water used in making completely saturated paste of the samples. The field capacity was determined by using the following Eq. (1):

Field capacity $=$ saturation percentage $/ 2$

Since the weight of each plastic pot plus filled soil and the moisture contents therein at the time of sowing were already known, therefore the weight of each filled plastic pot containing moisture contents equal to control. So, $70 \%$ and $35 \%$ field capacities were calculated representing a drought treatment.

Field capacity was maintained for each treatment (35\% and $70 \%$, respectively). The value of field capacity of soil in pots was checked by weighing pots with help of balance. Pots were only watered, if value of field capacity decreases. At maturity, root samples for each drought treatment were collected for morphological and anatomical studies. The root length, and fresh and dry weight of collected root samples were measured. Number of secondary roots was also counted. 


\subsection{Anatomical Characteristics}

Root anatomy was studied from a piece of $2 \mathrm{~cm}$ length of tap root from the root-shoot junction. The material was first fixed in formalin acetic alcohol (FAA) solution, with v/v 5\% formalin, 10\% acetic acid, 50\% ethanol and 35\% distilled water for about $72 \mathrm{~h}$. The material was subsequently transferred to acetic alcohol solution (v/v acetic acid 25\%, ethanol 75\%) for long-term preservation.

Freehand sections of about $50 \mu \mathrm{m}$ thick were cut and the selected sections were double stained with safranin-fast green technique. Stains used were safranin (1 g dissolved in $100 \mathrm{~mL}$ of $70 \%$ alcohol) and fast green ( $1 \mathrm{~g}$ dissolved in $100 \mathrm{~mL}$ of 90\% alcohol). Five uniform sections were selected at random for observation. After washing with xylene for enhancing contrast, the sections were mounted in Canada balsam for permanent slides. The following anatomical measurements were performed with the help of ocular micrometer mounted in compound microscope and were calibrated with stage micrometer: (1) thickness of whole root; (2) thickness of epidermis and cortex; (3) area of epidermis, cortex, sclerenchyma cells, phloem, protoxylem and metaxylem vessels, xylem vessel region; (4) diameter of medullary rays.

\subsection{Statistical Analysis}

A two way analysis of variance (ANOVA) of data for all the measurements was figured out under completely randomized design. Treatment means were compared by least significant difference (LSD) test at 5\% probability level [18].

\section{Results and Discussion}

\subsection{Root Morphology}

Morphological studies exposed variation in root growth of 12 chickpea cultivars. Number of secondary roots counting showed that proliferation and branching of the roots in CM45/04, CH47/04, CH587/05 and CH4/02 were profuse at field capacity of $70 \%$ and $35 \%$, whereas branching was less and limited in other cultivars. Depth of root system was estimated from the root length, and differences in rooting depth were observed at different field capacity of the soil. Increase in drought stress reduced the root length, fresh and dry weights of all cultivars. The root length was the highest in CH47/04, CH120/04 and CH119/04, followed by CH45/04, CH4/02 and CH587/05 at 70\% and 35\% drought stress. Very less variation in root diameter was observed at root-shoot junction of 12 chickpea cultivars. CH119/04 cultivar had the thinnest root of $0.157 \mathrm{~cm}$ at $70 \%$ field capacity and $0.14 \mathrm{~cm}$ at $35 \%$ field capacity. Among other cultivars, CH47/04, CH42/03 and CH587/05 produced relatively thicker roots with root diameter ranging from $0.2 \mathrm{~cm}$ to $0.3 \mathrm{~cm}$ (Fig. 1). A marked reduction in root length of chickpea (Cicer arietinum L.) cultivars was noticed under drought as shown in potato [19] and chickpea (Cicer arietinum L.) [20, 21]. In other studies, root fresh and dry weights were significantly reduced in chickpea [22-24], peanut [25], mung bean [26], white clover [27] and Erythrina seedling [28]. The root growth of some cultivars of chickpea (Cicer arietinum L.) was extremely decreased under drought stress in cereals [29, 30]. Morphological parameters showed that drought stress is cultivar specific even species specific. This cultivar specificity was observed in $\mathrm{CH} 42 / 03$ and $\mathrm{CH} 23 / 00$, in which the maximum reduction in morphological attributes was observed as compared to other cultivars. Cultivars CH587/05, CM45/05 and CH47/04 out of 12 chickpea cultivars have better root length and thickness with the maximum number of secondary roots. So these cultivars grow well under drought conditions.

\subsection{Root Sleeve}

Chickpea (Cicer arietinum L.) shows various anatomical alternations in roots under drought stress. Tissues exposed to environments with low water availability have generally shown reduction in cell size, and increase in vascular tissue and cell wall 


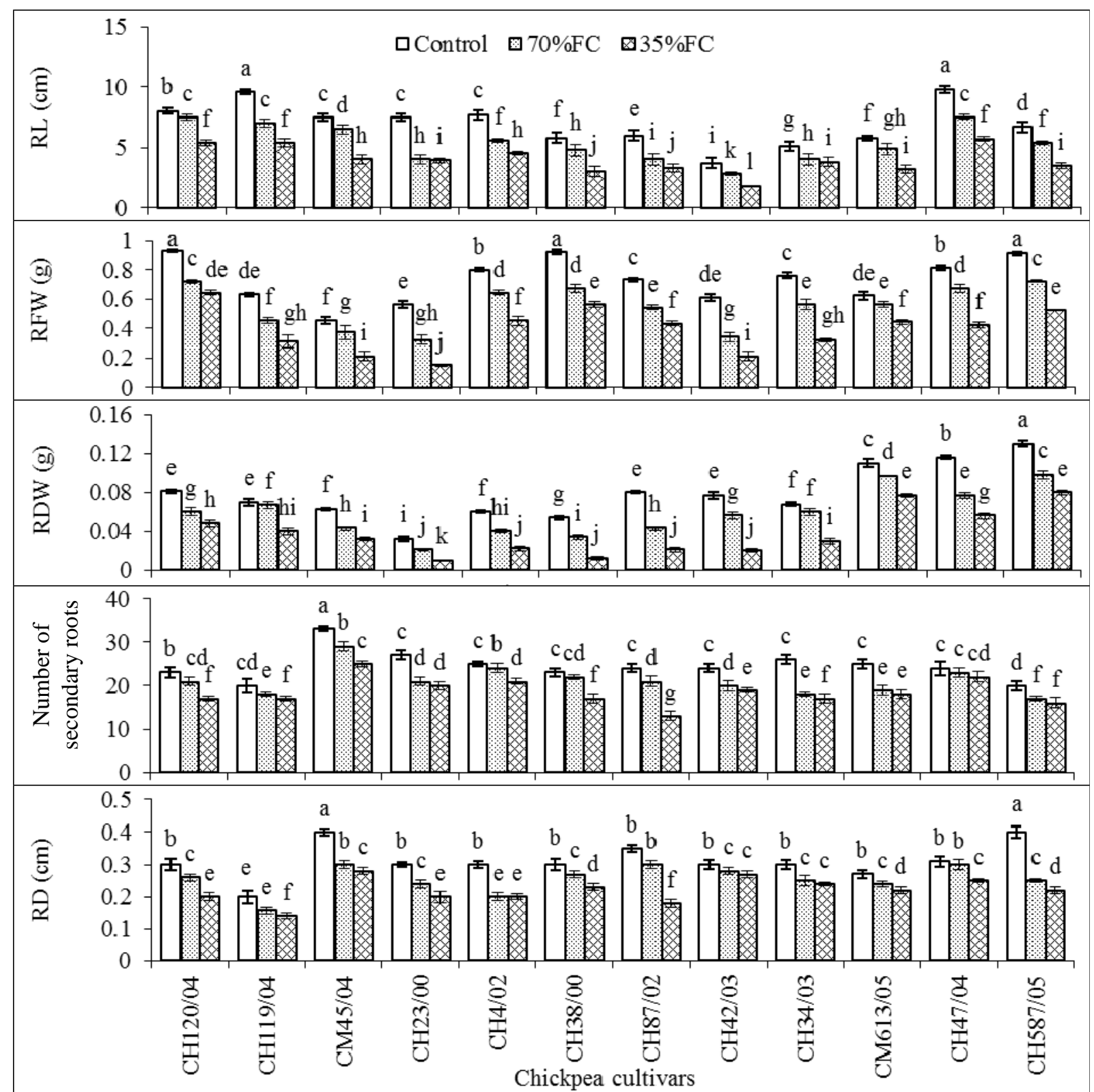

Fig. 1 Effect of drought (100\%, 70\% and 35\% field capacity) on root morphological attributes of 12 chickpea cultivars. $\mathrm{RL}=$ root length; RFW = root fresh weight; RDW = root dry weight; RD = root diameter; FC = field capacity.

Histogram and error bars represents means \pm standard deviation, ${ }^{\mathrm{a}-\mathrm{l}}$ represent the significance levels of treatments and cultivars $(P<$ 0.05).

thickness [31]. Thick epidermis is known to be useful in checking water loss under limited moisture conditions along with the thickness of cuticle layers. Larger cortical cell area seems to be related to better storage of moisture that is essential for survival under harsh climates [32].

Epidermis is the outermost cell layer of root that has direct contact with soil. Decrease or increase in soil water level in close vicinity of roots affects the epidermal cell size and thickness. Drought stress of $70 \%$ and $35 \%$ field capacity increased the thickness of epidermal cell layers in CM45/04, CH119/04, CH587/05 and CH47/04, the area of epidermal cells increased in CH587/05 and CH47/04, and the epidermal cell size reduced in CH42/03, CH34/03, CM613/05 and CH23/00, respectively. Decrease in 
field capacity of soil is responsible for small sclerenchymatous cell region, as well as cortical cell region. In dicotyledons, secondary growth resulted in shrinkage of cortical cell region. The largest cortex region with cortical cell area was measured in
CH87/02, CH120/04, CH119/04 and CH587/05, and the greater diameter of sclerenchymatous region was measured in $\mathrm{CH} 45 / 05$ and $\mathrm{CH} 4 / 02$. The sclerenchymatous cell area was smaller in CH587/05 and CH120/04, than other ten cultivars, with increasing

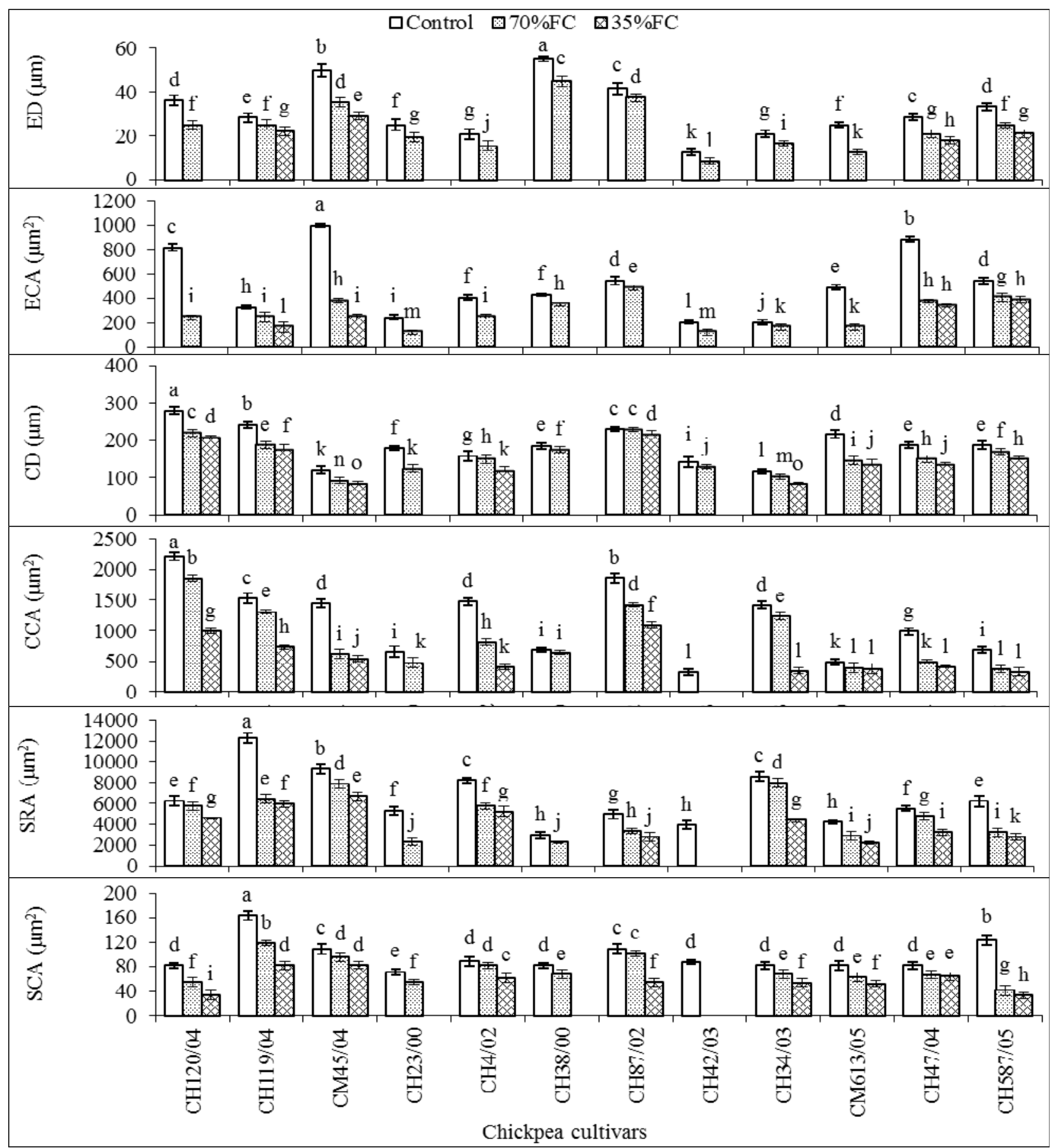

Fig. 2 Effect of drought (100\%, $\mathbf{7 0 \%}$ and $35 \%$ field capacity) on root sleeve tissues of 12 chickpea cultivars.

$\mathrm{ED}=$ epidermis diameter; ECA = epidermis cell area; $\mathrm{CD}$ = cortex diameter; CCA = cortex cell area; SRA = sclerenchyma region area; SCA = sclerenchymatous cell area; FC = field capacity.

Histogram and error bars represents means \pm standard deviation, ${ }^{\mathrm{a}-0}$ represent the significance levels of treatments and cultivars $(P<0.05)$. 

under Drought Stress Condition

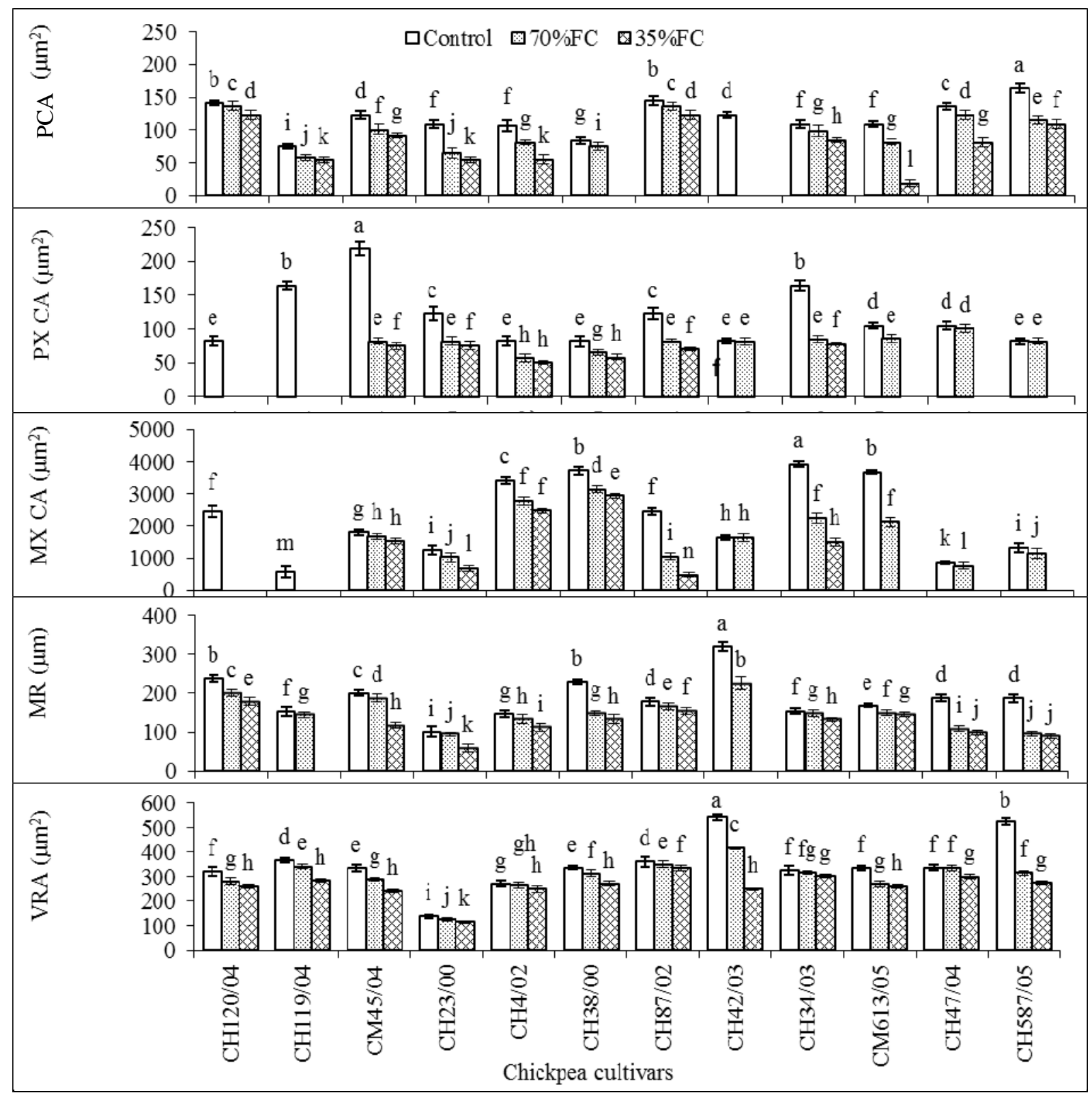

Fig. 3 Effect of drought (control, 70\% and 35\% field capacity) on root vascular tissues of 12 chickpea cultivars.

PCA = phloem cell area; PX CA = protoxylem cell area; MX CA = metaxylem cell area; MR = medullary rays; VRA = vascular region area.

Histogram and error bars represents means \pm standard deviation, ${ }^{\mathrm{a}-\mathrm{n}}$ represent the significance levels of treatments and cultivars $(P<$ 0.05).

field capacity of $70 \%$ and $30 \%$ as compared to their control (Fig. 2). The presence of sclerenchymatous layer and reduction in cortical cell region were reported as a consequence of secondary thickening [3].

\subsection{Vascular Tissue}

Vascular bundle area seems to be directly related to efficient transport of water and nutrients from the soil, and these might be of greater importance under low availability of moisture [33]. Larger protoxylem vessels can improve water and nutrient conduction [34], but at the same time, smaller metaxylem vessels may prevent embolism [35] and this again is beneficial under moisture deficit conditions. Large phloem area can enhance the conduction of assimilates [36]. 
The whole inner core is occupied by the xylem vessels with medullary rays barely visible in CH88/00, CH4/02, CH34/03, CM45/04, CH23/00 and CH87/02, while cultivars CH587/05, CH47/04 and $\mathrm{CH} 120 / 04$ had the largest area occupied with medullary rays with less metaxylem and protoxylem vessels. No crushing of protoxylem vessels due to secondary thickening and formation of metaxylem vessels was noticed in the 12 chickpea cultivars. The phloem is pushed more into the cortex towards the periphery of central xylem-dominated core of cultivars CH87/02, CH120/04, CH587/05 and CM45/04 with greater phloem cell area, as compared to CH613/05 and CH38/00 (Fig. 3). Among the cultivar studied, CH87/02, CH47/04, CH34/03 and CH587/05 showed more vascular region area with large number of metaxylem vessels, as well as small xylem vessels with the narrowest vascular diameter in $\mathrm{CH} 23 / 00$.

Under drought stress epidermis, cortex and xylem were decreased in common bean (Phaseolus vulgaris L.) [37]. Vessel diameters in stressed root were smaller than those in well-watered plants, and vascular tissue area was decreased by low soil moisture [38]. Drought decreased the diameter of the metaxylem bundle in Paspalum dilatatum and caused a reduction in the cortex to central cylinder ratio [39].

As well in this study, epidermal thickness was decreased under drought stress, cortical thickness, cortical cell area, sclerenchyma thickness, sclerenchyma region area, phloem cell area, protoxylem cell area, metaxylem cell area, vascular region area and medullary rays also were decreased under severe drought stress. These results are in agreement with those obtained by Lahlou and Ledent [19].

CH47/04 showed larger root length with thickened roots, decrease in fresh and dry weights at both field capacity of $70 \%$ and $35 \%$. Increase in number of secondary roots helps to absorb more water from the soil. Thickness of epidermis and cortical cells and increase in area of both the tissues help the root to prevent water loss and keep cells turgid. Presence of sclerenchymatous tissues just below the epidermis is another strategy opted by roots of cultivar $\mathrm{CH} 47 / 04$ to protect root from damage caused by drought stress. Severe water shortage may damage the xylem vessels, which kill the cells and make hollow space. Medullary rays increase the horizontal movement of water in tissues of CH120/04, CH4/02, CH47/04, CH587/05, and $\mathrm{CH} 87 / 02$, and high vascular region area improves the efficiency of upward movement of water in CH87/02, CH47/04, CH587/05 and $\mathrm{CH} 120 / 04$. Cultivars of chickpea CH42/02, CH23/00, CH119/04, CH120/04, CH613/05, CH38/00 and CH34/03 were devoid of anatomical modifications in roots similar to CH47/04 that made it vulnerable to drought stress at both field capacity of $70 \%$ and $35 \%$ as compared to control (100\% field capacity).

\section{Conclusions}

In conclusion, $\mathrm{CH} 47 / 04$ was highly tolerant among 12 cultivars of chickpea (Cicer arietinum L.) under drought stress, while $\mathrm{CH} 587 / 05$ and $\mathrm{CH} 87 / 02$ were moderately tolerant. CH42/03, CH23/00, CH119/04, CH120/04, CH613/05, CH38/00 and CH34/03 were drought sensitive cultivars. The genetic and molecular studies of the above mentioned morpho-anatomical modifications of roots under drought will help in developing genetically modified drought tolerant chickpea.

\section{References}

[1] Smart, K. 2011. Live the Smart Way: Gluten Free Cook Book. Toronto, Canada: Dundurn Press, 116.

[2] Shah, N. A., Aujla, K. M., Abbas, M., and Mahmood, K. 2007. "Economics of Chickpea Production in the Thal Desert of Pakistan.” Pak. J. Life Soc. Sci. 5: 6-10.

[3] Purushothaman, R., Zaman-Allah, M., Mallikarjuna, N., Pannirselvam, R., Krishnamurthy, L., and Gowda, C. L. L. 2013. "Root Anatomical Traits and Their Possible Contribution to Drought Tolerance in Grain Legumes.” Plant Prod. Sci. 16 (1): 1-8.

[4] Chandler, J. N., and Bartels, D. 2008. "Drought: Avoidance and Adaptation”. In Encyclopedia of Water Science, edited by Trimble, S. W., Stewart, B. A., and Howel, T. A. London: Taylor and Francis Group, 224. 
[5] Aroca, R., Ferrante, A., Vernieri, P., and Chrispels, M. J. 2006. "Drought, Abscisic Acid and Transpiration Rate Effects on the Regulation of PIP Aquaporin Gene Expression and Abundance in Phaseolus vulgaris Plants.” Ann. Bot. 98 (6): 1301-10.

[6] Gonzales, L., and Gonzales-Vilar, M. 2001. “Determination of Relative Water Content.” In Handbook of Plant Ecophysiology Techniques, edited by Reigosa, M. J. Dordrecht: Kluwer Academic Publishers, 207-12.

[7] Isendahl, N., and Schmidt, G. 2006. Drought in the Mediterranean: WWF Policy Proposals. A WWF Report, Madrid.

[8] Hongbo, Y., Wang, G., Zhang, G., and Wang, X. 2005. “The Second-Preimage Attack on MD4.” In Cryptology and Network Security. Heidelberg, Berlin: Springer, 1-12.

[9] Chaves, M. M., and Oliveira, M. M. 2004. "Mechanisms Underlying Plant Resilience to Water Deficits: Prospects for Water-Saving Agriculture.” J. Exp. Bot. 55 (407): 2365-84.

[10] Jaleel, C. A., Maniyannan, P., Sankar, B., Kishorekumar, A., Gopi, R., Somasundaram, R., and Panneerselyam, R. 2007. "Water Deficit Stress Mitigation by Calcium Chloride in Catharanthus roseus: Effects on Oxidative Stress, Proline Metabolism and Indole Alkaloid Accumulation.” Colloids Surf. B: Biointerfaces 60 (1): 110-6.

[11] Mostajeran, A., and Rahimi-Eichi, V. 2008. "Drought Stress Effects on Root Anatomical Characteristics of Rice Cultivars (Oryza sativa L.).” Pak. J. Biol. Sci. 11 (18): 2173-83.

[12] Ladjal, M., Huc, R., and Ducrey, M. 2005. "Drought Effects on Hydraulic Conductivity and Xylem Vulnerability to Embolism in Diverse Species and Provenances of Mediterranean Cedars.” Tree Physiol. 25 (9): 1109-17.

[13] Brunner, I., Herzog, C., Dawes, M. A., Arend, M., and Sperisen, C. 2015. "How Tree Roots Respond to Drought?” Front. Plant Sci. 6: 547.

[14] Matsui, T., and Singh, B. B. 2003. "Root Characteristics in Cowpea Related to Drought Tolerance at the Seedling Stage.” Exp. Agric. 39: 29-38.

[15] Benjamin, J. G., and Nielsen, D. C. 2006. "Water Deficit Effects on Root Distribution of Soy Bean, Field Pea and Chickpea.” Field Crops Res. 97 (2-3): 248-53.

[16] Kashiwagi, J., Krishnamurthy, L., Crouch, J. H., and Serraj, R. 2006. "Variability of Root Length Density and Its Contributions to Seed Yield in Chickpea (Cicer arietimum L.) under Terminal Drought Stress.” Field Crops Res. 95 (2-3): 171-81.

[17] Nejad, T. S. 2011. "Effect of Drought Stress on Root/Shoot Ratio." World Acad. Sci. Technol. 57: 598-600.
[18] Steel, R. G. D., Torrie, J. H., and Dickey, D. A. 1996. Principles and Procedures of Statistics: A Biometrical Approach, 3rd ed.. New York, USA: McGraw Hill Co..

[19] Lahlou, O., and Ledent, J. 2005. "Root Mass and Depth, Stolons and Roots Formed on Stolons in Four Cultivars of Potato under Water Stress.” Eur. J. Agron. 22 (2): 159-73.

[20] Enstone, D. E., Peterson, C. A., and Ma, F. 2003. "Root Endodermis and Exodermis: Structure, Function and Responses to the Environment.” J. Plant Growth Regul. 21 (4): 335-51.

[21] Romdhane, S. B., Trabelsi, M., Aouani, M. E., De Lajudie, P., and Mhamdi, R. 2009. "The Diversity of Rhizobia Nodulating Chickpea (Cicer arietinum L.) under Water Deficiency as a Source of More Efficient Inoculants.” Soil Biol. Biochem. 41 (12): 2568-72.

[22] Yaqoob, M., Holington, P. A., and Gorham, J. 2012. "Shoots, Root and Flowering Time Studies in Chickpea (Cicer arietinum L.) under Two Moisture Regimes.” Emir. J. Food Agric. 24 (1): 73-8.

[23] Najed, T. S., Bakhshande, A., Nasab, S. B., and Payande, K. 2010. "Effect of Drought Stress on Corn Root Growth." Report and Opinion 2 (2): 47-52.

[24] Yucel, D. O., Anlarsal, A. E., Mart, D., and Yucel, C. 2010. "Effects of Drought Stress on Early Seedling Growth of Chickpea (Cicer arietinum L.) Genotype.” World App. Sci. J. 11 (4): 478-85.

[25] Songsri, P., Jogloy, S., Vorasoot, N., Akkasaeng, C., Patanothai, A., and Holbrook, C. C. 2008. "Root Distribution of Drought-Resistant Peanut Genotypes in Response to Drought.” J. Agron. Crop Sci. 194 (2): 92-103.

[26] Tawfik, K. M. 2008. "Effect of Water Stress in Addition to Potassiomag Application on Mungbean.” Aust. J. Basic App. Sci. 2: 42-52.

[27] Nichols, S. N., Hofmann, R. W., Verry, I. M., and Williams, W. M. 2013. "Improved Drought Stress Tolerance of White Clover through Hybridization with Trifolium uniflorum L..” In Proceedings of the 22nd International Grassland Congress on Understanding Stress Physiology of Grasses and Forages, 115-7.

[28] Ciriaco da Silva, E., Silva, M. F. A., Noqueira, R. J. M. C., and Albuquerque, M. B. 2010. "Growth Evaluation and Water Relations of Erythrina velutina Seedlings in Response to Drought Stress.” Braz. J. Plant Physiol. 22 (4): 225-33.

[29] Yaqoob, M., Hollington, P. A., Mahar, A. B., and Gurmani, Z. A. 2013. "Yield Performance and Responses Studies of Chickpea (Cicer arietinum L.) Genotypes under Drought Stress.” Emir. J. Food Agric. 25 (2): 117-23.

[30] Rich, S. M., and Watt, M. 2013. "Soil Conditions and 


\section{Morpho-Anatomical Changes in Roots of Chickpea (Cicer arietinum L.) under Drought Stress Condition}

Cereal Root System Architecture: Review and Considerations for Linking Darwina and Weaver.” J. Exp. Bot. 64 (5): 1193-208.

[31] Guerfel, M., Baccouri, O., Boujnah, D., Chaibi, W., and Zarrouk, M. 2009. "Impacts of Water Stress on Gas Exchange, Water Relations, Chlorophyll Content and Leaf Structure in the Two Main Tunisian Olive (Olea europaea L.) Cultivars.” Sci. Horti. 119 (3): 257-63.

[32] Kanwal, H., Hameed, M., Nawaz, T., Ahmad, M. S. A., and Younis, A. 2012. "Structural Adaptations for Adaptability in Some Exotic and Naturalized Species of Agavaceae.” Pak. J. Bot. 44 (1): 129-34.

[33] Gostin, I. N. 2011. "Anatomical and Micromorphological Peculiarities of Adonis vernalis L. (Ranunculaceae).” Pak. J. Bot. 43 (2): 811-20.

[34] Chlewa, E., and Griffith, M. 2004. "The Unusual Vascular Structure of the Corn of Eriophorum vaginatum: Implications for Efficient Retranslocation of Nutrients.” $J$. Exp. Bot. 55: 731-41.
[35] Facette, M. R., McCully, M. E., Shane, M. W., and Canny, M. J. 2001. "Measurements of the Time to Refill Embolized Vessels.” Plant Physiol. Biochem. 39 (1): 59-66.

[36] Hose, E., Clarkson, D. T., Steudle, E., Schreiber, L., and Hartung, W. 2001. "The Exodermis: A Variable Apoplastic Barrier.” J. Exp. Bot. 52 (365): 2245-64.

[37] Pena-Valdivia, C. B., Sanchez-Urdaneta, A. B., Rangel, J. M., Munoz, J. J., Garcia-Nava, R., and Velazquez, R. C. 2010. “Anatomical Root Variations in Response to Water Deficit: Wild and Domesticated Common Bean (Phaseolus vulgaris L.).” Biol. Res. 43 (4): 417-27.

[38] Makbul, S., Saruhan-Guler, N., Durmus, N., and Guven, S. 2011. "Changes in Anatomical and Physiological Parameters of Soybean under Drought Stress.” Turk. J. Bot. 35 (4): 369-77.

[39] Vasellati, V., Oesterheld, M., Medan, D., and Loreti, J. 2001. "Effects of Flooding and Drought on the Anatomy of Paspalum dilatatum.” Ann. Bot. 88 (3): 355-60. 